\title{
ANALYSIS OF A THREE-STAGE SUPPLY CHAIN WITH LEVEL CONSTRAINTS
}

\author{
Buchmeister, B. ; Friscic, D. ${ }^{* *}$; Lalic, B. ${ }^{* * *} \&$ Palcic, I. \\ ${ }^{*}$ University of Maribor, Faculty of Mechanical Engineering, Smetanova 17, SI-2000 Maribor, Slovenia \\ ${ }^{* *}$ CIMOS TAM Ai, d.o.o., Perhavceva 21, SI-2000 Maribor, Slovenia \\ ${ }^{* * *}$ University of Novi Sad, Faculty of Technical Sciences, Trg Dositeja Obradovica 6, \\ 21000 Novi Sad, Serbia \\ E-Mail: borut.buchmeister@um.si
}

\begin{abstract}
Many companies have enjoyed a significant success due to the unique ways in which they have organized their supply chains, which are one of the best ways to compete in today's marketplaces. For make-to-stock production systems the production plans and activities are based on demand forecasting. This is one of the key causes of the bullwhip effect. The bullwhip effect (BE) is the inherent increase in demand fluctuation up the supply chain. In the paper we experimented (by simulating) with a special case of a simple three-stage supply chain using seasonal and deseasonalized time series of the market demand data in order to identify, illustrate and discuss the impacts of different level constraints on the BE. The results are presented for different overall equipment effectiveness (OEE) and constrained inventory policies. At higher $O E E$ level there is less variability in production processes, but at inventory limitations the impact is more complex.

(Received in December 2011, accepted in July 2012. This paper was with the authors 2 months for 2 revisions.)
\end{abstract}

Key Words: Bullwhip Effect, Supply Chains, Spreadsheet Simulation, Real Demand Data, Level Constraints

\section{INTRODUCTION}

Supply chain management (SCM) is one of the most important and developing areas. It includes basically demand fulfilment, demand planning and supply planning. It integrates internal and external logistics across many manufacturers, suppliers, distributors, retailers, and transportation providers to increase productivity and to obtain a competitive advantage for all parties involved (Fig. 1). The objective of supply chain management is to provide a high velocity flow of high quality, relevant information that will enable suppliers to provide an uninterrupted and precisely timed flow of materials to customers. The idea is to apply a total systems approach to managing the entire flow of information, materials, and services from raw materials suppliers through factories and warehouses to the end customer.

The original motive of SCM was "elimination of barriers between trading partners" in order to facilitate synchronization of information between them [1-3]. But in real business this idea became lost. Where is the main problem? Supply chain performance depends on the operation of all members in a supply chain, where each member's basic objective is the optimisation of its own performance. Such behaviour of members can lead to less optimal whole chain performance. Members of a supply chain are used to compete and not to cooperate; they don't share information about products, customers, inventories, production capacities, costs and other business processes. So the members do not know much about the real market situation and the efficiency in their chain. They just repeat five basic activities in their supply chain: buy, make, move, store and sell. 


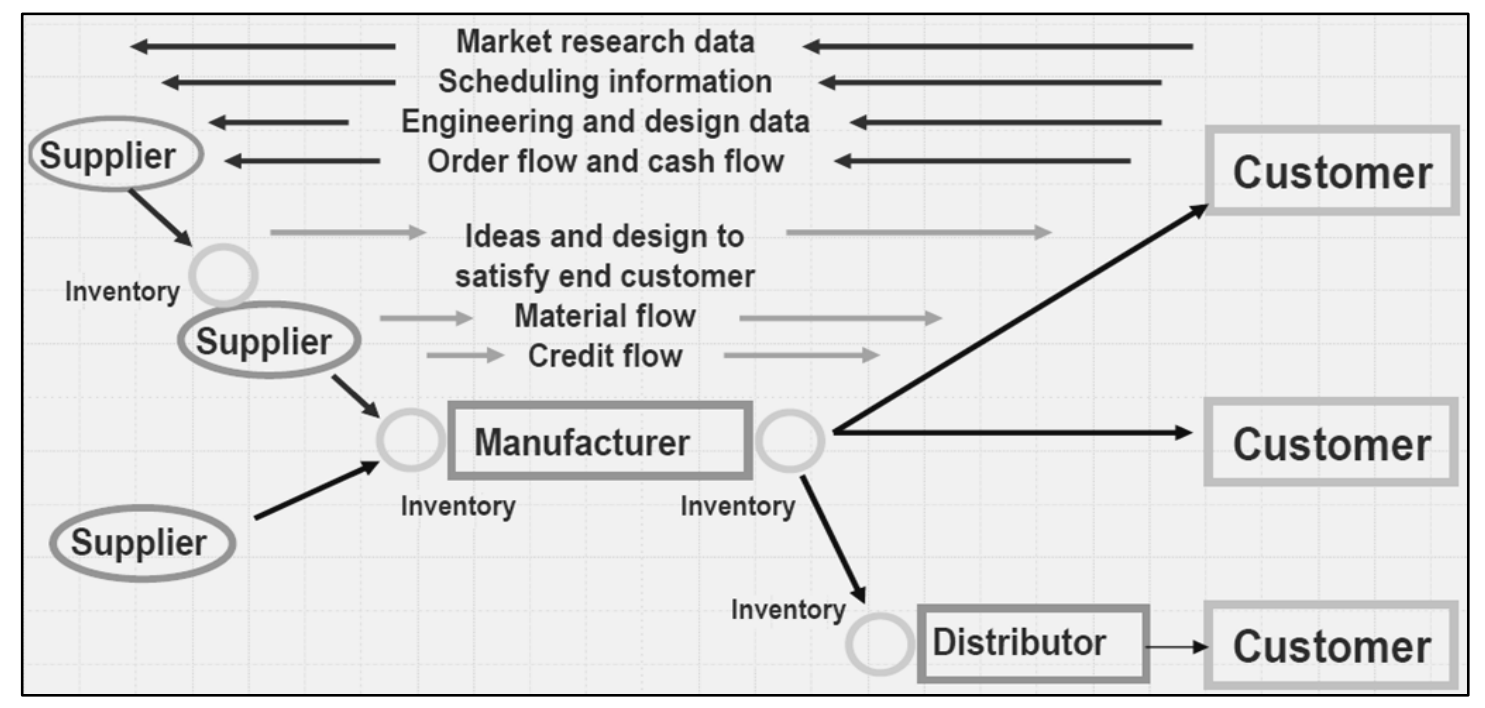

Figure 1: Flows in a supply chain (information, material, money).

Simulation is a very powerful and widely used management science technique [4-6] for the analysis and study of supply chains. The most important types are: spreadsheet simulation, system dynamics, discrete-event simulation, and business games.

The bullwhip effect represents the phenomenon of demand distortion where orders to supplier tend to have larger variance than sales to the buyer and this distortion propagates upstream in an amplified form.

Many companies are faced with the bullwhip effect and its consequences, but to understand the causes it is helpful to study it in a controlled environment. Eliminating the bullwhip effect can then increase product profitability by approximately $15-20 \%$.

In the paper we are giving a brief literature review of newer publications dealing with the bullwhip effect (section 2), continued with the presentation of the data used in the model (section 3) and our analysis of the influence of level constraints in the modelled supply chain (sections 4 and 5). Finally, section 6 contains a conclusion of the work and the future work.

\section{LITERATURE REVIEW}

Numerous studies focused on identifying the bullwhip effect in examples from individual products and companies. In our previous publications $[7,8]$ the literature review about related work regarding bullwhip effect from its first observations including causes and consequences has been presented [9-11] and we will not repeat that again. Only some selected papers from the last five years will be summarised.

We start with the supply chains. Carvalho and Machado presented a review of actual (lean, agile, resilient, green) SCM paradigms [12], identifying the attributes of each paradigm and their impact/consequence in the supply chain. They presented a conceptual model to provide the necessary understanding of synergies and divergences of paradigms and investigated the possibility to merge them, in order to contribute for a more sustainable and competitive supply chain. Pochampally et al. addressed the metrics that help evaluate the performance of reverse and closed-loop supply chains [13]. These metrics are incorporated in a mathematical model that uses quality function deployment (QFD) and linear physical programming (LPP) effectively to measure the 'satisfaction level' of the supply chain. Pishvaee et al. proposed a robust optimization model for handling the inherent uncertainty of input data in a closed-loop supply chain network design problem, which is the one of the primary works in this field [14]. The related semi-definite model is formulated according to 
studied uncertain parameters. Computational results show the superiority of the proposed model in both handling the uncertain data and the robustness of respective solutions against to the solutions obtained by the deterministic model.

Alony and Munoz reviewed the various methods of modelling the dynamics of supply chains [15]. They examined the limitations of modelling methodologies (analytical, agentbased, simulation) and suggested a combined discrete event and continuous simulation modelling approach. Pujawan investigated how different supply chain policies and different operating environments affect schedule instability in a supply chain [16]. It is shown that schedule instability is propagated up the supply chain and is much affected by the degree of demand uncertainty from the end customers, and that safety stock policy applied by the buyer has much impact on schedule instability. Bronja presented a multi-criteria mathematical model (based on AHP method) for ranking suppliers in multi-supplier environment [17].

Disney reviewed a range of methodological approaches for solving the bullwhip problem [18]. Measures for the bullwhip are given. Different types of supply chains (traditional - Fig. 2 , information sharing, vendor managed inventory) are described and as a whole it is a general overview including also replenishment policies, forecasting techniques, lead times, costs etc.

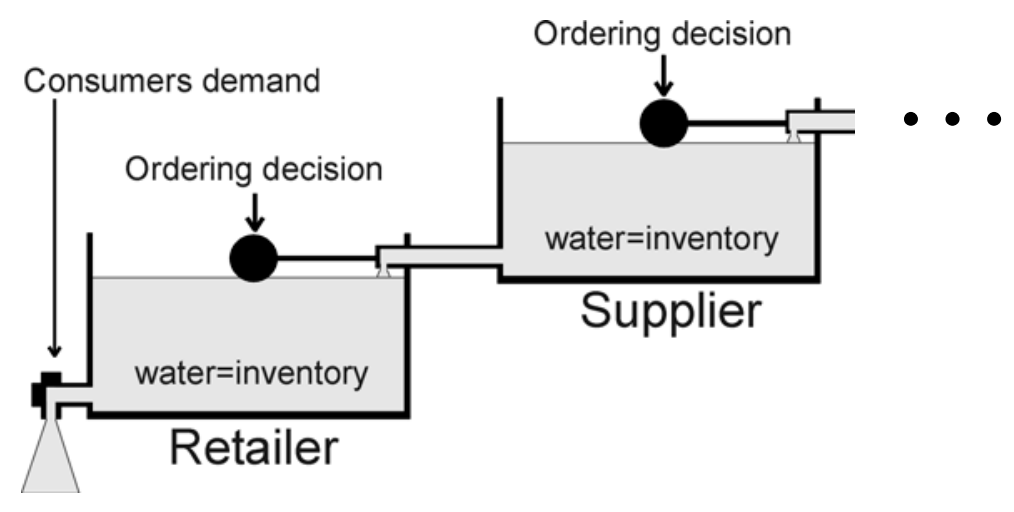

Figure 2: Schematic of a traditional supply chain [18].

Ouyang and $\mathrm{Li}$ analysed the propagation and amplification of order fluctuations in supply chain networks (with multiple customers) operated with linear and time-invariant inventory management policies [19]. The paper gives analytical conditions to predict the presence of the bullwhip effect to any network structure and any inventory replenishment policy, using a system control framework for analysing order stability. It provides the basis for modelling complex interactions among suppliers and among customer demands.

Glatzel et al. [20] described the bullwhip effect problem on many practical cases from global manufacturing industry aspect with the emphasis to find new ways of thinking and decision making to assure enough flexibility in business. Cachon et al. made observations and evaluated the strength of the bullwhip effect in U.S. industry [21] using official data from period 1992-2006. They did not observe the bullwhip effect among retailers and among manufacturers, but the majority of wholesalers amplified. They explained also that highly seasonal industries tend to smooth demand volatility whereas nonseasonal industries tend to amplify.

Chen and Lee [22] developed a set of formulas that describe the traditional bullwhip measure as a combined outcome of several important drivers (finite capacity, batch ordering, seasonality). They discussed the managerial implications of the bullwhip measurement and showed that an aggregated measurement over relatively long time periods can mask the operational-level bullwhip. Duc et al. [23] quantified the bullwhip effect, the variance amplification in replenishment orders, for cases of stochastic demand and stochastic lead time in a two-stage supply chain. They investigated the behaviour of a measure for the bullwhip 
effect with respect to autoregressive coefficient and stochastic order lead time. Sucky focused in his work [24] on measuring the bullwhip effect taking into consideration the network structure of supply chains. He shows that the bullwhip effect is overestimated if just a simple (two stage) supply chain is assumed and risk pooling effects are present. The strength of the effect depends on the statistical correlation of the demands. Ouyang and Daganzo [25] presented a control framework to analyse the bullwhip effect in single-stage supply chain under exogenous Markovian uncertainty. They derived robust analytical conditions that diagnose the bullwhip effect and bound its magnitude. The results are useful for prediction of performance in uncertain operating environments.

Shaikh and Khan quantified twenty factors responsible for the bullwhip effect [26]. Their study is based on Middle East situation; the data were collected using a questionnaire. The most critical factors observed are Substitution products (Competition) and Seasonal effect.

Agrawal et al. analysed a two stage serial supply chain [27]. They studied the impact of information sharing and lead time on bullwhip effect and on-hand inventory. It is shown that some part of bullwhip effect always remain after sharing both inter- and intra-stage data and that the lead time reduction is far more beneficial. Bray and Mendelson analysed the bullwhip by information transmission lead time based on public companies' data from years 1974-2008. Shorter reaction times cause significantly more troubles regarding bullwhip [28].

Oyatoye in Fabson [29] explored the simulation approach in quantifying the effect of bullwhip in supply chain, using various forecasting methods. They emphasized a problem of inadequate information in a supply chain. Kelepouris et al. studied how specific replenishment parameters affect order variability amplification, product fill rates and inventory levels across the chain [30]. Short lead times are essential for the efficient operation of the supply chain. They investigated also how demand information sharing can help towards reducing order oscillations and inventory levels in upper nodes of a supply chain. The model represents a simple two-stage supply chain with real demand data. Tominaga et al. investigated the influence of safety parameters for inventory control policy (safety stocks) on bullwhip effect and its relationship to costs and total profit, with present demand uncertainty in the modelled supply chain [31]. Csik and Foldesi tested the problem of bullwhip effect by adoption of an inventory replenishment policy involving a variable target level, where all other common causes were excluded [32]. Safety stock was proportional to the actual demand. They proposed a new production plan, which guarantees the stability of the entire supply chain.

Nepal et al. presented an analysis of the bullwhip effect and net-stock amplification in a three-stage supply chain considering step-changes in the production rates during a product's life-cycle demand [33]. The simulation results show that performance of a system as a whole deteriorates when there is a step-change in the life-cycle demand.

Akkermans and Voss checked the bullwhip effect in services [34]. They investigated how this effect manifests itself in services (differently: build-ups of work backlogs, peaks of workloads, customer calls and complaints), which are the drivers (behaviour) and which actions trigger (lack of visibility) or mitigate (reduction of work backlog) the bullwhip effect.

\section{DATA AND MODEL PRESENTATION}

Our study is dealing with single product / multi-level supply chain using real market demand data with present variability (demand with moderate linear trend, we calculate with seasonality and deseasonalized). Information (orders) in the chain flow on a weekly basis. We have collected a time series of the market demand data with seasonal characteristics for 48 weeks (= periods; in their order of occurrence all are given in Table I), shown also in Fig. 3 where we added the deseasonalized values for the time series. 
Table I: Market demand variation for the single product (original values).

\begin{tabular}{|c|c|c|c|c|c|c|c|c|c|c|c|c|}
\hline Weeks 1-12 & 48 & 65 & 85 & 117 & 134 & 143 & 145 & 122 & 90 & 83 & 55 & 51 \\
\hline Weeks 13-24 & 54 & 61 & 97 & 145 & 138 & 144 & 135 & 121 & 89 & 81 & 52 & 26 \\
\hline Weeks 25-36 & 44 & 61 & 87 & 131 & 139 & 157 & 155 & 154 & 106 & 89 & 44 & 38 \\
\hline Weeks 37-48 & 54 & 76 & 119 & 154 & 172 & 179 & 166 & 152 & 121 & 97 & 51 & 48 \\
\hline
\end{tabular}

Statistical analysis shows that we have 48 data, minimal demand is 26 items, and maximal demand is 179. Average demand is 102; mode 97, standard deviation is 43 (for original demand) and 11 (for deseasonalized demand).

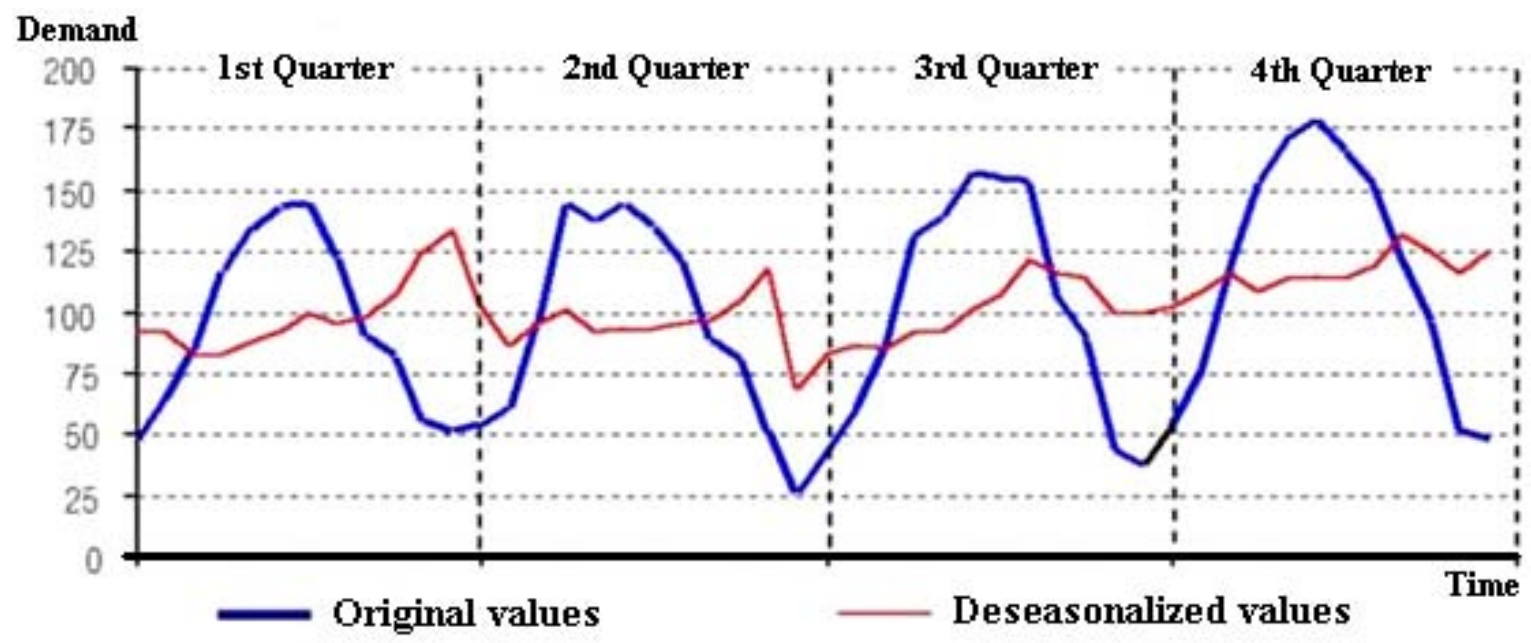

Figure 3: Market demand of the product (original and deseasonalized values).

Deseasonalization is performed using the chain indexing method. In all models (SM seasonal model and DSM - deseasonalized model) the 48 periods with continuous reviewing were simulated. The simulation model comprises a three-stage supply chain consisting from single retailer, manufacturer and supplier (Fig. 4).

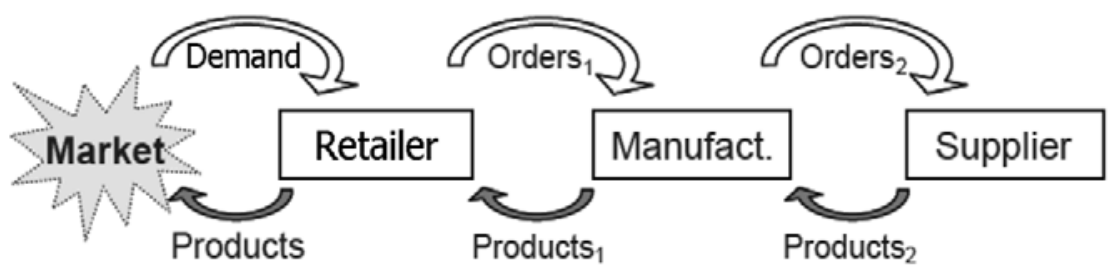

Figure 4: Presentation of a three-stage supply chain.

The simulation spreadsheets are designed in Microsoft Excel software (file size $270 \mathrm{~kb}$ ). For inventory policy, as one level constraint, we have chosen the min-max inventory policy but only for manufacturer stage in the supply chain. Manufacturer places the order to its supplier in predetermined review period. The order size is the difference between the required production level and the effective inventory level at the review time. Effective level is quantity of work in progress, net stock level plus backorder quantity:

Order $=$ required production level - work in progress - net stock level + backorder quantity

Inventory level is defined as:

$$
M I N \text { inv. level }=S S \cdot S f
$$


where:

$$
\text { MAX inv. level }=\text { MIN inv. level } \cdot \text { INVlf }
$$

SS - safety stock,

Sf - safety stock factor,

INVIf - inventory level factor (1 ... 2).
MIN inv. level - minimum inventory level, MAX inv. level - maximum inventory level,

SS is considered as emergency inventory and should be lower or equal to minimum level, which is at lowest equal to average retailer demand. $S f$ determines safety level between minimum inventory level and SS. In the models we have determined $S f$ at $30 \%$ of $S S$.

$I N V l f$ is used in the models to regulate inventories between minimum and maximum level. With higher INVfl stock fluctuates at higher amplitude, what leads to a bigger net stock amplification. We assume limited warehouse space with upper bound of 206 items which equals twice the average demand. Therefore we have limited INVfl in a range from 1 to 2 .

Considering $S f$ the $S S$ is defined at limit where the minimum inventory level satisfies production rate and capacity utilization planed according to retailers demand. Usually the processes are planned at $85 \%$ of OEE where production output totally complies with retailers demand and capacity utilization meets $100 \%$ (later in Fig. 5).

Considering the aforementioned for the second level constrain we have chosen the $O E E$ factor, which is considered in manufacturer and supplier lead time. Total lead time is the time taken by the demand and order to be processed to the retailer - review period. It consists of manufacturer and supplier lead time.

$$
\begin{gathered}
L m=\frac{T m}{O E E m} \\
L s=\frac{T s}{\text { OEEs }} \\
L=L m+L s \\
P R=\frac{D}{L} \\
C U=\frac{P R}{\operatorname{maxPR}} \times 100
\end{gathered}
$$

where:
$L m$ - manufacturer lead time,
$\mathrm{Tm}$ - manufacturer production lead time,
Ls - supplier lead time,
$L$ - total lead time,
Ts - supplier production lead time,
$P R$ - production rate,
$D$ - retailer's demand,
$C U$ - capacity utilization in \%.

In this paper, for the bullwhip effect measure, the following equation is used:

$$
B E=\frac{V A R(\text { Order })}{\operatorname{VAR}(\text { Demand })}
$$

If the value of $B E$ is equal to one, then the order and demand variances are equal. Bullwhip effect is present in a supply chain if its value is larger than one. When the value of bullwhip is smaller than one it is assumed to have a smoothing scenario, meaning that the orders are less variable than the demand pattern.

Net stock amplification $\left(N S_{a m p}\right)$ is calculated as a ratio between max-min inventory level and demand variances:

$$
N S_{\text {amp }}=\frac{\operatorname{VAR}(\text { Max-min inventory level })}{\operatorname{VAR}(\text { Demand })}
$$

Verification of the outputs of the model was done by tracing the values produced by the simulation and verifying them by hand using the mathematical equations from the model. 
In real environment, because of various deviations in production process, the process is hardly $100 \%$ smooth. Therefore the OEE level is taken into account. The BE level equal to one is more theoretical because the difference between order variability and demand pattern is always present. We also assume that higher order variability and strength of the $B E$ can be reduced with proper inventory level policy. Some other assumptions in the model:

- The three-stage supply chain is working with a decentralized information sharing policy, where each stage calculates its demand forecast, based on the orders it gets from the downstream stage.

- Inventory control is based on continuous review ordering policy, where a new order is placed when the inventory level drops to the minimum inventory level.

- At manufacturer stage the inventory levelling policy is performed.

- Backorders are allowed, thus if one of the inventories cannot fulfil the whole order, it will keep the shortage amount as a backorder to be fulfilled as soon as it gets a new replenishment.

- Time series model: retailer performs autoregressive $\operatorname{AR}(1)$ model with $0<\varphi<1$ for the demand pattern and manufacturer performs exponential smoothing with $0<\alpha<1$ for demand forecasting. If the regression coefficient $\varphi$ is close to 0 , then the process demand looks like white noise, but as $\varphi$ approaches to one, the output gets a larger contribution from the previous demand relative to the noise, resulting in a smoothing scenario. In both models $\varphi$ is 0,25 , so it is allowed that previous demands and the noise term contribute to the output of demand pattern. If exponential smoothing parameter $\alpha$ is close to 0 , then older data are more important for prediction. In both models the precise data are required, so $\alpha$ is 0,1 .

- The OEE level is considered at manufacturer and supplier lead time to fulfil the orders.

- The review period is equal to total lead time.

- Week is the basic time unit in the model. One order per period (week) is presumed for each stage in the chain.

- The simulation starts with a stock amount equal to minimum required inventory level.

- If the inventory stock exceeds the target level, then the order equals zero. This means: no order is performed in that period.

\section{SIMULATION}

The aim of the simulation is to investigate the phenomenon of the bullwhip effect and identify the impact of different level constraints. The simulation model demonstrates the situation in 49 weeks. In the next three subsections the results of the supply chain model for different $O E E$ and inventory levels are presented.

\subsection{Case 1: Equal $O E E m$ and $O E E s(85 \%)$, and inventory policy with defined $S S$ and planed $S f$ and $I N V I f$}

Production processes are planed at OEE of $85 \%$ and $C U$ of $100 \%$ where $P R$ meets the required amount of demand. Considering this, an effective inventory policy has to be chosen with sufficient SS, efficient Sf and INVIf. Presence of deviation (OEE level) in production process causes higher order variability than demand pattern, which results in higher $B E$ than one.

Case 1 (Fig. 5) indicates stronger BE in DSM. Because of constant demand and unsteady production process, stock fluctuates more easily, which means more frequent order variability. Because of this phenomenon the difference between order and demand variances 
is higher. In order to reduce the $B E$ on reasonable level effective inventory policy have to be performed.

\begin{tabular}{l|c|c|c|c}
\hline BULLWHIP & 1,83 NET STOCK AMPLIFICATION & 0,22 COSTUMER SERVICE LEVEL & $100,00 \%$ FILL RATE & $100,00 \%$ \\
MAX INV. LEVEL & 155 MANUF. PR. RATE & $100,00 \%$ AVERAGE INVENTORY COST PER PERIOD & $368,29 €$ \\
MIN INV. LEVEL & 103,00 SUPPL. PR. RATE & $100,00 \%$ AVERAGE SWITCHING COST PER PERIOD & $158,08 €$
\end{tabular}

\begin{tabular}{l|r|rr}
\hline SAFETY STOCK & $\mathbf{7 9}$ SAFETY STOCK FACTOR & $\mathbf{1 , 3}$ INVENTORY LEVEL FACTOR & $\mathbf{1 , 5}$ \\
MANUF. OEE & $\mathbf{0 , 8 5}$ SUPPL. OEE & $\mathbf{0 , 8 5}$ Lm & $\mathbf{1}$ LS \\
\hline
\end{tabular}

\section{DESEASONALIZED MODEL RESULTS}

\begin{tabular}{|c|c|c|c|c|}
\hline BULLWHIP & 2,94 NET STOCK AMPLIFICATION & 0,65 COSTUMER SERVICE LEVEL & $100,00 \%$ FILL RATE & $100,00 \%$ \\
\hline MAX INV. LEVEL & 155 MANUF. CAP. UTILIZAT. & $100,00 \%$ AVERAGE INVENTORY COST PER PERIOD & $329,30 €$ & \\
\hline
\end{tabular}

MIN INV. LEVEL $\quad 103,00$ SUPPL. CAP. UTILIZAT. $\quad 100,00 \%$ AVERAGE SWITCHING COST PER PERIOD

\begin{tabular}{l|r|rr}
\hline SAFETY STOCK & $\mathbf{7 9}$ SAFETY STOCK FACTOR & $\mathbf{1 , 3}$ INVENTORY LEVEL FACTOR & $\mathbf{1 , 5}$ \\
MANUF. OEE & $\mathbf{0 , 8 5}$ SUPPL. OEE & $\mathbf{0 , 8 5}$ Lm & $\mathbf{1}$ LS \\
\hline
\end{tabular}

LEGEND

INSERTED VARIABLES

SIMULATION RESULTS

Figure 5: Model results at OEEm and OEEs of $85 \%$.

In both models the same inventory policy has been chosen. Thus higher $B E$ and $N S_{a m p}$, the DSM is more cost efficient because of lower max-min inventory level variance which indicates more frequent stock fluctuation and order variability at lower amplitude (Fig. 6).

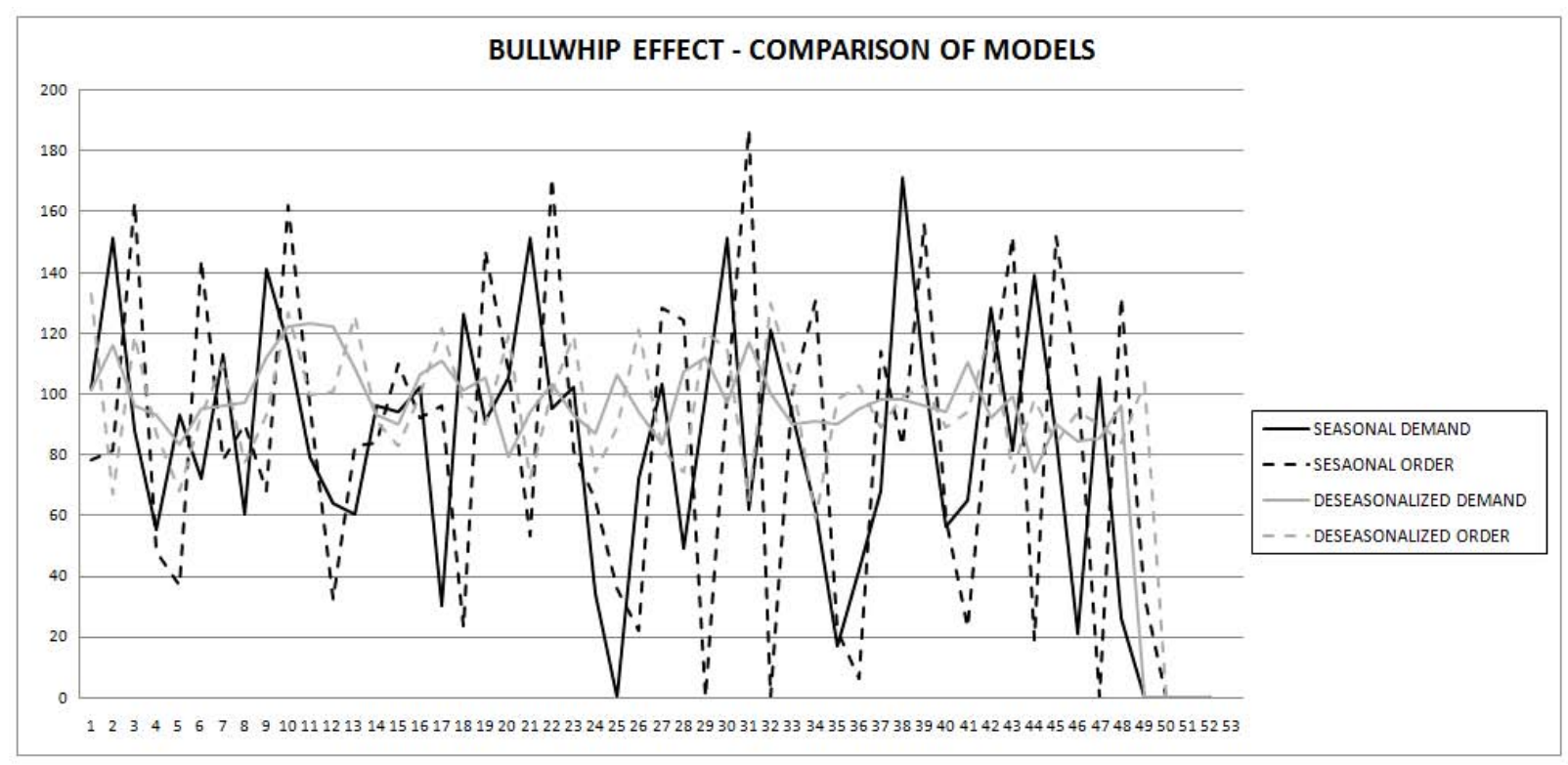

Figure 6: Case 1 bullwhip effect comparison.

\subsection{Case 2: Different $O E E m$ and $O E E s(85 \%, 75 \%)$ and changed inventory policy with defined $S S$ and variation of $S f$ and $I N V I f$}

Different levels of $O E E$ at downstream stages in a supply chain daily occur in real environment. Downstream stage has higher deviations in production processes; that leads 
often to inefficient material supply. Incoming inventory level fluctuates more at upstream stage which leads to backorders and higher order variability.

\begin{tabular}{l|c|c|c|c}
\hline BULLWHIP & 1,55 NET STOCK AMPLIFICATION & 0,16 COSTUMER SERVICE LEVEL & $100,00 \%$ FILL RATE & $100,00 \%$ \\
MAX INV. LEVEL & 178 MANUF. PR. RATE & $100,00 \%$ AVERAGE INVENTORY COST PER PERIOD & $\mathbf{3 6 1 , 8 8} €$ & \\
MIN INV. LEVEL & 111,00 SUPPL. PR. RATE & $114,00 \%$ AVERAGE SWITCHING COST PER PERIOD & $\mathbf{1 1 4 , 9 2 €}$ &
\end{tabular}

\begin{tabular}{l|l|c|c|c}
\hline SAFETY STOCK & $\mathbf{7 9}$ SAFETY STOCK FACTOR & $\mathbf{1 , 4}$ INVENTORY LEVEL FACTOR & $\mathbf{1 , 6}$ & $\mathbf{1}$ \\
MANUF. OEE & $\mathbf{0 , 8 5}$ SUPPL. OEE & $\mathbf{0 , 7 5}$ Lm & $\mathbf{1}$ LS & $\mathbf{1}$
\end{tabular}

\section{DESEASONALIZED MODEL RESULTS}

\begin{tabular}{|c|c|c|c|c|}
\hline BULLWHIP & 2,75 NET STOCK AMPLIFICATION & 0,04 COSTUMER SERVICE LEVEL & $100,00 \%$ FILL RATE & $100,00 \%$ \\
\hline MAX INV. LEVEL & 133 MANUF. CAP. UTILIZAT. & $100,00 \%$ AVERAGE INVENTORY COST PER PERIOD & $340,80 €$ & \\
\hline MIN INV. LEVEL & 111,00 SUPPL. CAP. UTILIZAT. & $114,00 \%$ AVERAGE SWITCHING COST PER PERIOD & $45,21 €$ & \\
\hline
\end{tabular}

\begin{tabular}{l|r|rr}
\hline SAFETY STOCK & $\mathbf{7 9}$ SAFETY STOCK FACTOR & $\mathbf{1 , 4}$ INVENTORY LEVEL FACTOR & $\mathbf{1 , 2}$ \\
MANUF. OEE & $\mathbf{0 , 8 5}$ SUPPL. OEE & $\mathbf{0 , 7 5}$ Lm & $\mathbf{1}$ LS \\
\hline
\end{tabular}

Figure 7: Different OEEm (85\%) and OEEs (75\%), with variations of INVIf and Sf.

In Case 2 (Fig. 7) simulation results indicate more frequent inventory fluctuation, due to downstream backlogs. Therefore in both models the net stock amplification and $B E$ was stronger than in Case 1 . To reduce the strength of $B E$, we must reduce the order variability. For this matter the inventory level has to be optimized. In Case 2 the INVIf in both models was changed. In SM model INVlf and $S f$ were raised for $10 \%$ to increase minimum and maximum inventory on sufficient level. So peaks out of limits were eliminated, stock fluctuation was stabilized and variance of min-max stock level was reduced. Also order variability was decreased (Fig. 8).

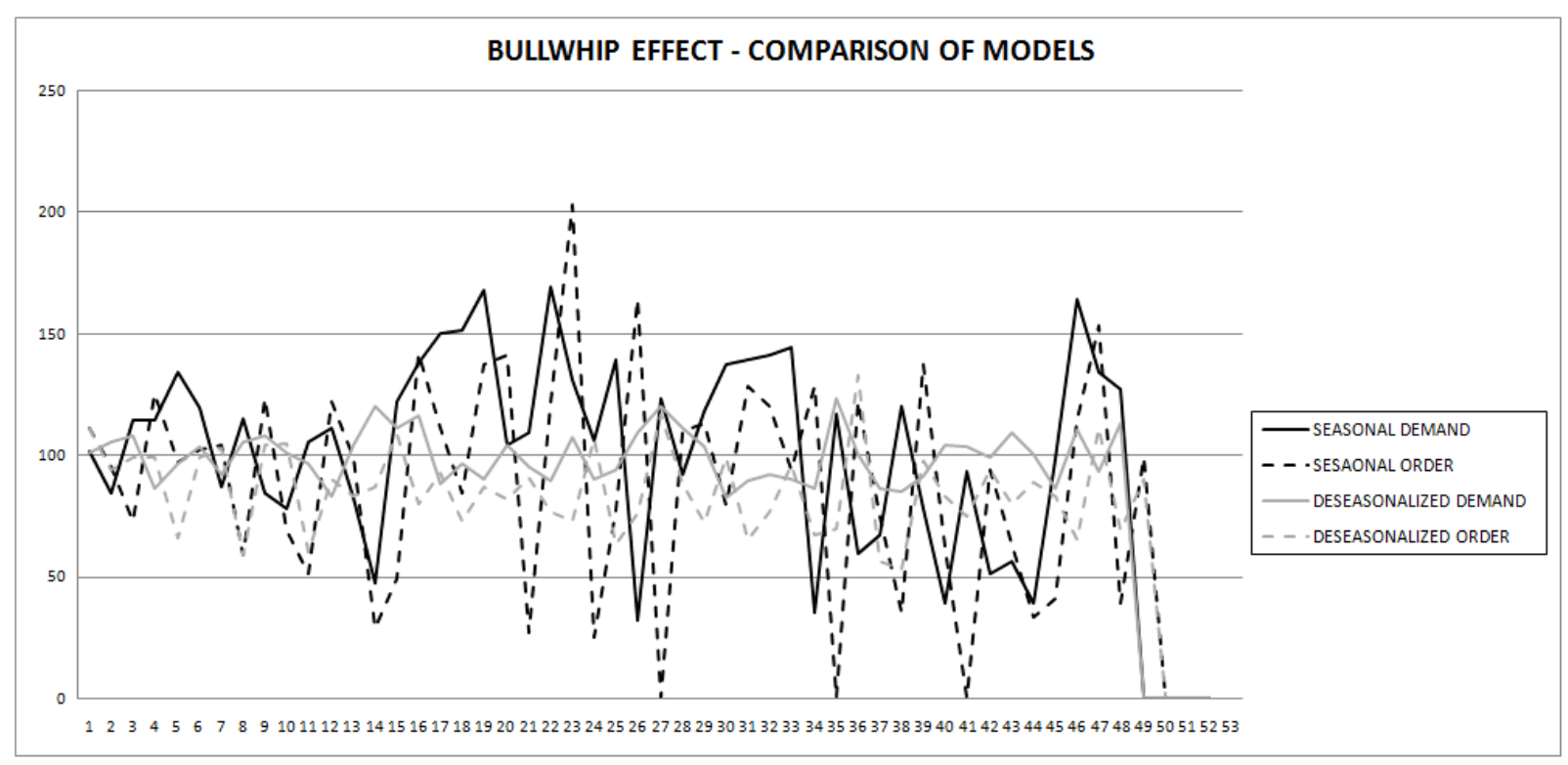

Figure 8: Case 2 bullwhip effect comparison.

Due to more unsteady stock fluctuation, changes are more frequent, which is more evident in DSM. To reduce the BE in DSM the inventory level has to be optimized. INVIf was decreased and $S f$ was increased; that has raised the minimum inventory level and has lowered the maximum level. With this optimization amplitude of stock fluctuation was reduced and 
variance of min-max inventory level is reduced. Due to more limited inventory level and steady demand pattern the order variability is frequent at lower amplitude, leading to stronger $B E$ in DSM.

Usually manufacturer cannot influence on supplier problems in production process. But the inventory can be stabilized with adapted inventory policy, with changing and properly defining $S f$ and $I N V I f$ for optimum min-max inventory levels and for reducing $B E$.

\subsection{Case 3: Equal $O E E m$ and $O E E s(100 \%)$ and changed inventory policy with defined $S S$ and variation of $S f$ and $I N V I f$ of 1,5}

OEE of $100 \%$ is more theoretical and can occur under ideal conditions. Despite prediction the deviation between demand and orders downstream in the supply chain occurs (Fig. 9).

\section{SEASONAL MODEL RESULTS}

\begin{tabular}{|c|c|c|c|c|}
\hline BULLWHIP & 1,20 NET STOCK AMPLIFICATION & 0,23 COSTUMER SERVICE LEVEL & $100,00 \%$ FILL RATE & $100,00 \%$ \\
\hline MAX INV. LEVEL & 155 MANUF. PR. RATE & $85,00 \%$ AVERAGE INVENTORY COST PER PERIOD & $374,69 €$ & \\
\hline MIN INV. LEVEL & 103,00 SUPPL. PR. RATE & $85,00 \%$ AVERAGE SWITCHING COST PER PERIOD & $126,21 €$ & \\
\hline
\end{tabular}

\begin{tabular}{l|c|r|r|}
\hline SAFETY STOCK & $\mathbf{7 9}$ SAFETY STOCK FACTOR & $\mathbf{1 , 3}$ INVENTORY LEVEL FACTOR & $\mathbf{1 , 5}$ \\
MANUF. OEE & $\mathbf{1 , 0 0}$ SUPPL. OEE & $\mathbf{1 , 0 0}$ Lm & $\mathbf{1}$ LS \\
\hline
\end{tabular}

DESEASONALIZED MODEL RESULTS

\begin{tabular}{|c|c|c|c|c|}
\hline BULLWHIP & 1,57 NET STOCK AMPLIFICATION & 0,60 COSTUMER SERVICE LEVEL & $100,00 \%$ FILL RATE & $100,00 \%$ \\
\hline MAX INV. LEVEL & 155 MANUF. CAP. UTILIZAT. & $85,00 \%$ AVERAGE INVENTORY COST PER PERIOD & $328,62 €$ & \\
\hline MIN INV. LEVEL & 103,00 SUPPL. CAP. UTILIZAT. & $85,00 \%$ AVERAGE SWITCHING COST PER PERIOD & $27,92 €$ & \\
\hline
\end{tabular}

\begin{tabular}{l|r|r|r|}
\hline SAFETY STOCK & $\mathbf{7 9}$ SAFETY STOCK FACTOR & $\mathbf{1 , 3}$ INVENTORY LEVEL FACTOR & $\mathbf{1 , 5}$ \\
MANUF. OEE & $\mathbf{1 , 0 0}$ SUPPL. OEE & $\mathbf{1 , 0 0} \mathrm{Lm}$ & $\mathbf{1}$ LS \\
\hline
\end{tabular}

Figure 9: Model results at OEEm and OEEs of $100 \%$.

Simulation has shown the difference in variance between order and demand in both models; more evident is in DSM, because of order variability at constant demand pattern. Therefore the $B E$ even at $100 \%$ of $O E E$ is not equal to one (Fig. 10).

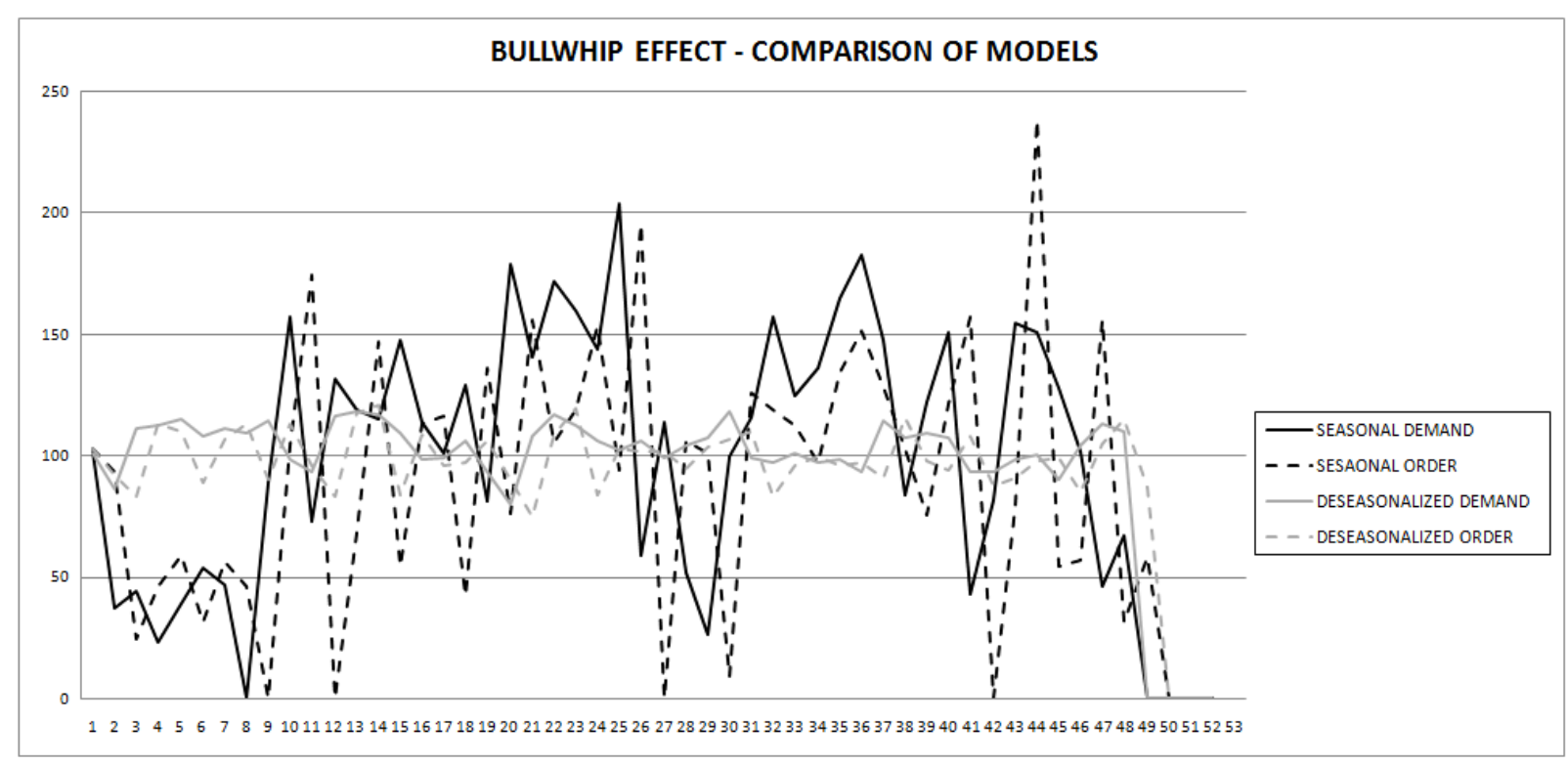

Figure 10: Case 3 bullwhip effect comparison. 
Simulation results indicate more cost effective DSM at the same level of costumer delivery compliance because of lower min-max inventory level variance. $B E$ and $N S_{a m p}$ are stronger in DSM because of constant demand pattern where stock fluctuates more frequently and orders are more varable than the demand pattern.

\subsection{Comparison of the results for all three cases}

Simulation results (Table II) indicate the weakest $B E$ in Case 3, where ideal conditions (OEE of $100 \%$ ) on all downstream stages in the supply chain were simulated. Case 2 is more likely in the real environment, where with proper inventory policy the $B E$ was reduced.

Table II: Comparison of $B E$ and variance coefficient (VC) for cases 1, 2, and 3.

\begin{tabular}{|ll|c|c|c|}
\hline \multicolumn{2}{|c|}{} & Case 1 & Case 2 & Case 3 \\
\hline & $B E_{S M}$ & 1,85 & 1,55 & 1,20 \\
& $B E_{D S M}$ & 2,94 & 2,75 & 1,57 \\
\hline Demand & $V C_{S M}$ & 0,42 & 0,40 & 0,47 \\
Orders & $V C_{S M}$ & 0,70 & 0,94 & 0,64 \\
\hline Demand & $V C_{D S M}$ & 0,022 & 0,021 & 0,016 \\
Orders & $V C_{D S M}$ & 0,057 & 0,156 & 0,026 \\
\hline
\end{tabular}

The demand and order variance coefficient is calculated as:

$$
\begin{aligned}
& \text { Demand VC }=\frac{V A R\left(\text { Demand }^{4}\right.}{\sum_{i=1}^{48} \text { Demand }_{i}} \\
& \text { Order } V C=\frac{V A R(\text { Order })}{\sum_{i=1}^{48} \text { Order }_{i}}
\end{aligned}
$$

In all three cases the variance coefficient $(V C)$ is higher in SM than in DSM due to less limited inventory policy and seasonal characteristic of time series. Because of higher order variability the order variance coefficient in all three cases for both models is higher than demand variance coefficient due to presence of $O E E$ levels downstream the supply chain.

Results indicate that at higher $O E E$ level the order variability is lower, consequently the strength of $B E$ is lower. Inventory optimization in Case 2 results in reducing the $B E$ and $N S_{a m p}$. Therefore the $B E$ in Case 2 is lower than in Case 1, where inventory optimization was not performed. Due to more unsteady material flow through the supply chain in Case 2 order variance coefficient is the biggest. Because of $\mathrm{AR}(1)$ for demand pattern and excluded influence of $O E E$ level in production process at the retailer stage the demand variance coefficient is at the same level in all three cases, but due to deseasonalization in DSM is lower than in SM.

Additional analysis includes a comparison of net stock amplification $\left(N S_{a m p}\right)$ for both models and all three cases, which is shown in Fig. 11.

For DSM and SM in all three cases the SS is set up at the same level of 79 items. Due to different inventory policies there are differences in volume of inventory min-max level:

- In Case 1 the same inventory policy with $S f$ of 1,3 and INVlf of 1,5 for both models has been used. In SM inventories fluctuate around average of 120 with intervals from minimum level of 103 to maximum level of 155 items, but in DSM the fluctuation is around average of 107 and between minimum level of 103 and maximum level of 140. In SM the fluctuation is characterised with more peaks, but inventories in DSM are more stable around minimum inventory level. 
- In Case 2 another inventory policy has been applied to mitigate the stock fluctuation, order variability and consequently strength of $B E$ at given $O E E$ level in the supply chain. In SM there are more peaks above the maximum inventory level which indicate that the limitation in SM was too restrictive. To avoid such phenomena the INVfl and Sf in SM were increased both for 0,1 , so that the inventory level was sufficient. The inventories are more stable and fluctuate around average 121 items with intervals from minimum level of 111 to maximum level of 178 items. In DSM the $S f$ was increased for 0,1, but regarding INVfl a decrease for 0,3 was needed. That means that there were insufficient minimum inventory level and excessive maximum level causing fluctuation of inventories with higher amplitude between min-max level and with peaks above minimum limit. With changed inventory policy the minimum level was raised and min-max level was narrowed, which leads to inventories with very small fluctuation around 111 items. The orders are more stable and that leads to lower $B E$ in both models.

- In Case 3 there is the same inventory policy as in Case 1 with the same min-max inventory level in both models. Due to more stable production process there is less order variability and the strength of $B E$ is smaller than in Case 1.

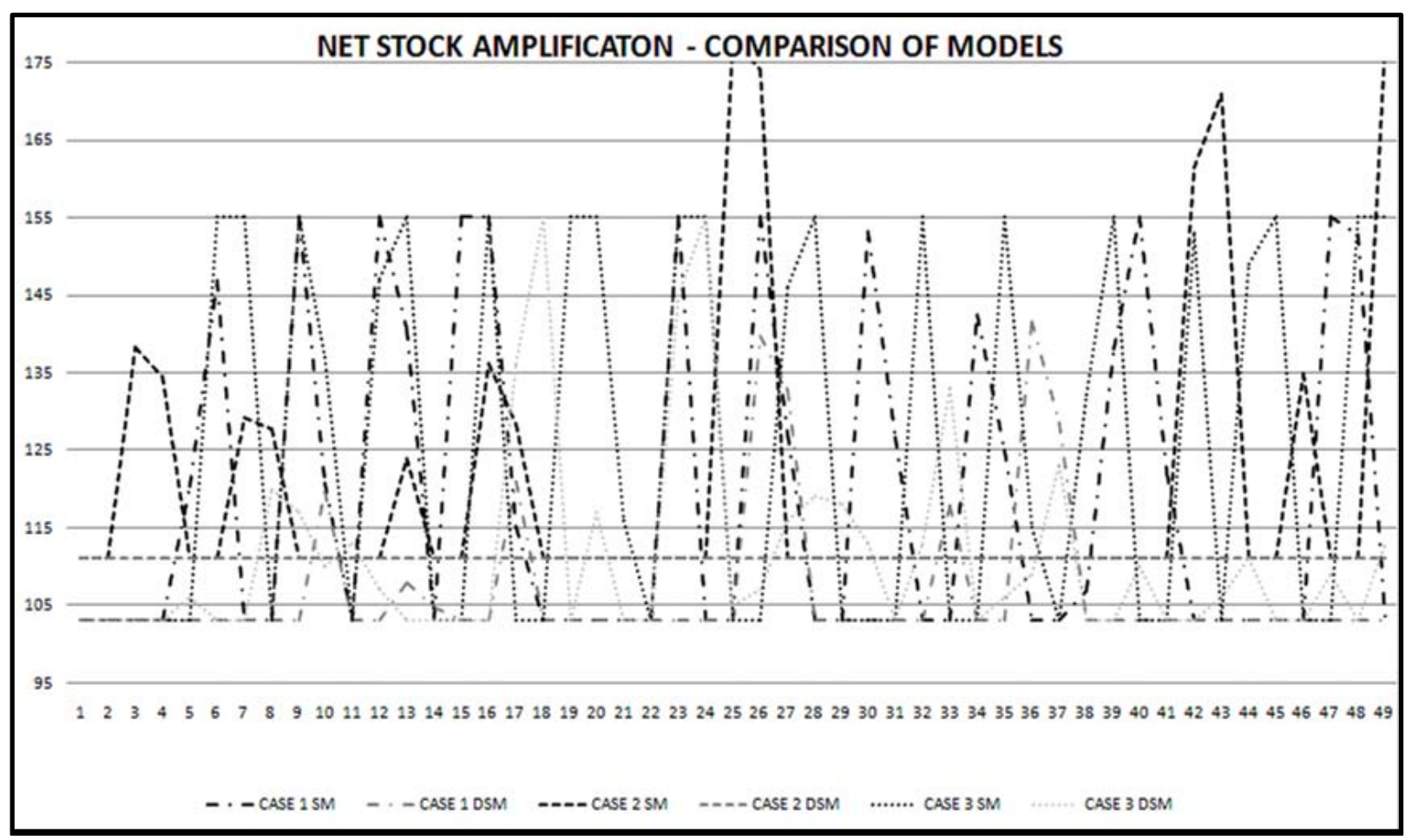

Figure 11: Comparison of net stock amplification (2 models, 3 cases).

\section{DISCUSSION}

Our analysis is based on a developed MS Excel spreadsheet supply chain simulation model, working on the min-max inventory policy. Three cases of seasonal and deseasonalized models have been investigated, regarding the link between changing constraints parameters (overall equipment effectiveness and inventory policy with variable safety factor and inventory level factor) and bullwhip strength.

We have found out that OEE level on downstream stages has a significant influence on inventory fluctuation and order variability in the supply chain. Higher deviation in production process (lower $O E E$ factor) causes more frequent stock fluctuations. This brings frequent 
order variability and stronger BE at constrained inventory level policy. We have noticed that changing the inventory level with variations of INVfl and $S f$ has influence on BE strength.

The $P R$ and $C U$ are better when $O E E$ increases (see Eqs. (4) to (8)). At higher OEE level manufacturers have less deviation in their production processes. Consequently orders to suppliers are more constant and more aligned with demand pattern. Therefore BE strength is lower. Because of constant demand pattern in DSM and non-steady manufacturer and supplier production rate, orders in DSM will vary more frequently than in SM. The difference between order and demand variance will be higher. Consequently at planed OEE level the BE will be stronger in DSM than in SM.

Considering OEE level in DSM, order variability is higher. When material flow is steadier than expected, level of $O E E$ will be higher than $85 \%$, meaning that the lead time decreases and $C U$ will be under $100 \%$. When level of OEE decreases below $85 \%$ then lead time increases and $C U$ will be more than $100 \%$ (e.g. more than 15 shifts per week). Stock consumption is more unsteady at lower OEE level.

The graphical presentation in Fig. 11 indicates less inventory fluctuation in DSM, thus $N S_{\text {amp }}$ is smaller in SM. This phenomenon occurs because of deseasonalization of time series where orders variation is higher than the demand pattern. Because of linkage between orders and inventory level, the ratio between inventory level variance and demand variance is higher in DSM.

The results indicate decreasing strength of $\mathrm{BE}$ at better $O E E$ level. At each $O E E$ level, some way of right inventory levelling policy must be performed. This means that the right amplitude of stock fluctuation has to be maintained, where the order variability will be at the appropriate level considering strength of BE in a supply chain.

\section{CONCLUSION}

Many manufacturers perform demand forecast in order to have steady material flow through production processes. They cannot predict various deviations in their processes which are calculated through different $O E E$ levels. Therefore they take into account $O E E$ level at their $P R$. This affects inventory planning and orders to suppliers which are usually higher than retailer demand. Results of simulation indicate that $O E E$ level and inventory level downstream the supply chain have a significant impact on order variability and its frequency through the chain.

We have illustrated the phenomenon of bullwhip effect using real demand data in three simulation cases of a supply chain with different level constraints (OEE, inventories).

At higher $O E E$ level there is less deviation in production processes. Efficient inventory policy enables that orders to suppliers are more constant and more aligned with the retailer demand. In this case the bullwhip effect and net stock amplification will be lower.

At predicted demand increase of variability in production process causes decreasing $O E E$ level. Without adjustments in inventory policy, the bullwhip effect and stock amplification will increase. In terms of supply chain efficiency that mean inefficient deliveries. Considering $O E E$ level and constant demand pattern in the DSM, more frequent order variability is required. Bullwhip effect is stronger in DSM. We can say that the BE is compensated by the variability generated by the seasonality. Simulation results also indicate more cost effective DSM than SM at the same level of costumer delivery compliance, because of lower required inventory lavel.

Our future research will be focused to more complex supply chains (networks), sharing the same suppliers, with more than one product, incorporating other real restrictions and combinations of stock keeping policies. We will study such circumstances and finally suggest the appropriate actions to mitigate the bullwhip effect. 


\section{REFERENCES}

[1] Gilbert, S. M.; Ballou, R. H. (1999). Supply chain benefits from advanced customer commitments, Journal of Operations Management, Vol. 18, No. 1, 61-73, doi:10.1016/S02726963(99)00012-1

[2] Vujica-Herzog, N.; Tonchia, S.; Polajnar, A. (2009). Linkages between manufacturing strategy, benchmarking, performance measurement and business process reengineering, Computers \& Industrial Engineering, Vol. 57, No. 3, 963-975, doi:10.1016/j.cie.2009.03.015

[3] Rudolf, R.; Anzel, I.; Markovic, E.; Colic, M.; Stamenkovic, D. (2012). Gold in the past, today and future, Metalurgija, Vol. 51, No. 2, 261-264

[4] Tan, Y.; Takakuwa, S. (2011). Use of Simulation in a Factory for Business Continuity Planning, International Journal of Simulation Modelling, Vol. 10, No. 1, 17-26, doi:10.2507/ IJSIMM10(1)2.172

[5] Al-Hawari, T.; Aqlan, F.; Al-Araidah, O. (2010). Performance Analysis of an Automated Production System with Queue Length Dependent Service Rates, International Journal of Simulation Modelling, Vol. 9, No. 4, 184-194, doi:10.2507/IJSIMM09(4)2.168

[6] Ben Said, L.; Hmiden, M.; Ghedira, K. (2010). A Two-Step Transshipment Model with Fuzzy Demands and Service Level Constraints, International Journal of Simulation Modelling, Vol. 9, No. 1, 40-52, doi:10.2507/IJSIMM09(1)4.142

[7] Buchmeister, B.; Pavlinjek, J.; Palcic, I.; Polajnar, A. (2008). Bullwhip effect problem in supply chains, Advances in Production Engineering \& Management, Vol. 3, No. 1, 45-55

[8] Buchmeister, B. (2008). Investigation of the bullwhip effect using spreadsheet simulation, International Journal of Simulation Modelling, Vol. 7, No. 1, 29-41, doi:10.2507/ IJSIMM07(1)3.093

[9] Forrester, J. W. (1961). Industrial dynamics, MIT Press, Cambridge

[10] Sterman, J. (1989). Modeling managerial behaviour: misperceptions of feedback in a dynamic decision making experiment, Management Science, Vol. 35, No. 3, 321-339, doi:10.1287/ mnsc.35.3.321

[11] Lee, L. H.; Padmanabhan, V.; Whang, S. (1997). Information distortion in a supply chain: the Bullwhip Effect, Management Science, Vol. 43, No. 4, 546-558, doi:10.1287/mnsc.43.4.546

[12] Carvalho, H.; Machado, V. C. (2009). Lean, agile, resilient and green supply chain: a review, Proceedings of the Third International Conference on Management Science and Engineering Management, Bangkok, Thailand, 59-69

[13] Pochampally, K. K.; Gupta, S. M.; Govindan, K. (2009). Metrics for performance measurement of a reverse/closed-loop supply chain, International Journal of Business Performance and Supply Chain Modelling, Vol. 1, No. 1, 8-32, doi:10.1504/IJBPSCM.2009.026263

[14] Pishvaee, M. S.; Rabbani, M.; Torabi, S. A. (2011). A robust optimization approach to closedloop supply chain network design under uncertainty, Applied Mathematical Modelling, Vol. 35, No. 2, 637-649, doi:10.1016/j.apm.2010.07.013

[15] Alony, I.; Munoz, A. (2007). The Bullwhip effect in complex supply chains, International Symposium on Communications and Information Technologies ISCIT 2007, 1355-1360

[16] Pujawan, I. N. (2008). Schedule instability in a supply chain: an experimental study, International Journal of Inventory Research, Vol. 1, No. 1, 53-66, doi:10.1504/IJIR.2008.019208

[17] Bronja, H. (2011). Multi-criteria approach to ranking suppliers in the supply chain concept, Technical Gazette, Vol. 18, No. 3, 393-401

[18] Disney, S. (2009). Bullwhip Effect in Supply Chains. SciTopics, from http://www.scitopics.com/Bullwhip_Effect_in_Supply_Chains.html, accessed on 13-12-2011

[19] Ouyang, Y.; Li, X. (2010). The bullwhip effect in supply chain networks, European Journal of Operational Research, Vol. 201, No. 3, 799-810, doi:10.1016/j.ejor.2009.03.051

[20] Glatzel, C.; Helmcke, S.; Wine, J. (2009). Building a flexible supply chain for uncertain times, The McKinsey Quarterly, March Issue, 5 pages

[21] Cachon, G. P.; Randall, T.; Schmidt, G. M. (2007). In search of the bullwhip effect, Manufacturing \& Service Operations Management, Vol. 9, No. 4, 457-479, doi:10.1287/ msom.1060.0149 
[22] Chen, L.; Lee, H. L. (2012). Bullwhip effect measurement and its implications, Operations Research, Vol. 60, No. 4, 771-784, doi:10.1287/opre.1120.1074

[23] Duc, T. T. H.; Luong, H. T.; Kim, Y.-D. (2008). A measure of the bullwhip effect in supply chains with stochastic lead time, International Journal of Advanced Manufacturing Technology, Vol. 38, No. 11-12, 1201-1212, doi:10.1007/s00170-007-1170-1

[24] Sucky, E. (2009). The bullwhip effect in supply chains - An overestimated problem?, International Journal of Production Economics, Vol. 118, No. 1, 311-322, doi:10.1016/ j.ijpe.2008.08.035

[25] Ouyang, Y.; Daganzo, C. (2008). Robust tests for the bullwhip effect in supply chains with stochastic dynamics, European Journal of Operational Research, Vol. 185, No. 1, 340-353, doi:10.1016/j.ejor.2006.10.046

[26] Shaikh, R.; Khan, M. A. (2008). Quantifying bullwhip effect and reducing its impact, from http://ssrn.com/abstract $=1263741$, accessed on 14-05-2012

[27] Agrawal, S.; Sengupta, R. N.; Shanker, K. (2009). Impact of information sharing and lead time on bullwhip effect and on-hand inventory, European Journal of Operational Research, Vol. 192, No. 2, 576-593, doi:10.1016/j.ejor.2007.09.015

[28] Bray, R. L.; Mendelson, H. (2012). Information transmission and the bullwhip effect: An empirical investigation, Management Science, Vol. 58, No. 5, 860-875, doi:10.1287/ mnsc.1110.1467

[29] Oyatoye, E. O.; Fabson, T. V. O. (2011). Information distortion in supply chain: A simulation approach to quantifying the bullwhip effect, Journal of Emerging Trends in Economics and Management Sciences, Vol. 2, No. 2, 131-141

[30] Kelepouris, T.; Miliotis, P.; Pramatari, K. (2008). The impact of replenishment parameters and information sharing on the bullwhip effect: A computational study, Computers \& Operations Research, Vol. 35, No. 11, 3657-3670, doi:10.1016/j.cor.2007.04.004

[31] Tominaga, H.; Nishi, T.; Konishi, M. (2008). Effects of inventory control on bullwhip in supply chain planning for multiple companies, International Journal of Innovative Computing, Information and Control, Vol. 4, No. 3, 513-529

[32] Csik, A.; Foldesi, P. (2012). A bullwhip type of instability induced by time varying target inventory in production chains, International Journal of Innovative Computing, Information and Control, Vol. 8, No. 8, 5885-5897

[33] Nepal, B.; Murat, A.; Chinnam, R. B. (2012). The bullwhip effect in capacitated supply chains with consideration for product life-cycle aspects, International Journal of Production Economics, Vol. 136, No. 2, 318-331, doi:10.1016/j.ijpe.2011.12.018

[34] Akkermans, H.; Voss, C. (2010). The service bullwhip effect, $17^{\text {th }}$ International Annual EurOMA Conference, Porto, 10 pages 